\title{
Epidermal Growth Factor Receptor Tyrosine Kinase Inhibitors in the Treatment of Patients with Non-small Cell Lung Cancer of Squamous Histology: Focus on Afatinib
}

\author{
Noemi Reguart and Roxana Reyes \\ Department of Medical Oncology, Thoracic Oncology Unit, Hospital Clínic Barcelona, Spain
}

DOI: https://doi.org/10.17925/OHR.2021.17.1.36

\begin{abstract}
mmunotherapy with immune checkpoint inhibitors, either as monotherapy or in combination with chemotherapy, is now established firstline treatment for patients with advanced non-small cell lung cancer (NSCLC) of squamous histology, and this requires optimization of treatments upon disease progression. Targeting the ErbB receptor family appears to provide benefit, and three agents targeting epidermal growth factor receptor are approved (afatinib, erlotinib and necitumumab). In this article, we aim to summarize the data supporting the use of afatinib for patients with NSCLC of squamous histology. In the LUX-Lung 8 study, afatinib significantly improved outcomes compared with erlotinib in patients with squamous NSCLC after progression to first-line platinum-based therapy. Notably, in patients achieving long-term benefit (defined as receiving afatinib treatment for $\geq 12$ months), ErbB family mutations were more frequently observed, and a median overall survival of 27.5 months was attained with afatinib treatment. About one-fifth of the patients had ErbB mutation-positive tumours, and in these patients, there was a more pronounced progression-free survival and overall survival benefit with afatinib compared with erlotinib. The safety profile in patients with squamous NSCLC is consistent with the known safety profile of afatinib, and includes diarrhoea, skin toxicities, fatigue and stomatitis as the most common side effects. Taken as a whole, afatinib could be considered for patients with advanced squamous-cell carcinoma of the lung, as an option in patients with disease that has failed previous treatment with chemotherapy and/or immunotherapy, and in the second-line setting in patients who are not eligible for immune checkpoint inhibitors.
\end{abstract}

\section{Keywords}

Non-small cell lung cancer, squamous-cell histology, ErbB family mutations, afatinib, erlotinib, HER2 mutations

Disclosures: Noemi Reguart has been a consultant or advisor to Boehringer Ingelheim, MSD, Roche, Guardant Health, Pfizer, Takeda, Novartis, Astra-Zeneca, and Lilly; and has received trial funding from Novartis and Pfizer. Roxana Reyes has no financial or non-financial relationships or activities to declare in relation to this article. This content has been partially presented previously at ESMO 2019 in Barcelona, Spain, in an industry-sponsored satellite symposium (Boehringer Ingelheim) "Making first- and second-line treatment decisions for advanced NSCLC", on 29 September 2019.

Acknowledgements: Medical writing assistance was provided by Aurora O'Brate and funded by Boehringer Ingelheim. Boehringer Ingelheim was given the opportunity to check the data used in this manuscript just for factual accuracy only.

Review process: Double-blind peer review.

Compliance with ethics: This study involves a review of the literature and did not involve any studies with human or animal subjects performed by any of the authors.

Authorship: The named authors meet the International Committee

of Medical Journal Editors (ICMJE) criteria for authorship of this

manuscript, take responsibility for the integrity of the work as a whole,

and have given final approval for the version to be published.

Access: This article is freely accessible at touchONCOLOGY.com

(C) Touch Medical Media 2020

Received: 17 August 2020

Accepted: 20 January 2021

Published online: 22 June 2021

Citation: touchREVIEWS in Oncology \& Haematology. 2021;17(1):36-41

Corresponding author: Noemi Reguart, Department of Medical Oncology,

Thoracic Oncology Unit, Hospital Clínic Barcelona. Translational Genomics and

Targeted Therapeutics in Solid Tumors, IDIBAPS. Villarroel 170, 08036 Barcelona, Spain.

E: nreguart@clinic.cat

Social media handle: @nreguart

Support: The publication of this article was supported by Boehringer Ingelheim. The views and opinions expressed are those of the author

and do not necessarily reflect those of Boehringer Ingelheim.
The treatment of patients with non-small cell lung cancer (NSCLC) has seen significant advances in the past decade, with the availability of multiple targeted therapy agents for oncogenic-driven non-squamous NSCLC and the advent of immunotherapy that has completely revolutionized the treatment of patients without oncogenic drivers. Consequently, the lives of patients with NSCLC have significantly improved. However, there is still a high unmet need for effective treatments after the disease progresses and this unmet need is even higher in patients with squamous-cell lung cancer because there are fewer treatments available for patients with this histology. ${ }^{1}$

There are differences in the demographic characteristics of the patients with NSCLC depending on the type of the histology. Adenocarcinoma is the most common type of lung cancer which stems from epithelial cells that line the larger airways. Squamous-cell carcinoma is the secondmost common type and stems from the peripheral small airways. They account for approximately $50 \%$ and $30 \%$, respectively, of all cases of NSCLC. ${ }^{2,3}$ Patients with adenocarcinoma tend to be younger with a higher prevalence in females and in never smokers than patients with squamous-cell carcinoma, who tend to be older, male and smokers.

Historically, all patients with NSCLC were treated with similar platinumbased combinations, independent of their histology, with similar benefit across the agents and regimens available. It was in 2000 that studies with new-generation antifolates and antiangiogenics suggested efficacy differences and safety issues according to the histology subtype. ${ }^{4-7}$ Initial studies with bevacizumab showed an increase in severe haemoptysis in patients with squamous-cell lung cancers, including fatal cases, so the use of bevacizumab has been routinely avoided in patients with squamous histology. ${ }^{4}$ Similarly, pemetrexed is not indicated for patients with squamous-cell carcinoma, in this case because of lower efficacy, 
likely due to the higher expression of thymidylate synthase, the primary target of pemetrexed in patients with this histology. ${ }^{5,6}$ Moreover, using pemetrexed as maintenance that significantly improved outcomes for patients with non-squamous NSCLC, ${ }^{7}$ has not been an option for patients with squamous histology, and has further increased the gap on treatment options available across the two major histologies.

Furthermore, advances in targeted therapy that have dramatically improved the lives of patients with adenocarcinoma through the identification of new treatable oncogenic drivers, have largely bypassed patients with squamous-cell lung cancers. ${ }^{1}$ The Cancer Genome Atlas, as well as other studies, has identified several genomically defined subsets of squamous NSCLC; however, these did not include any of the actionable oncogenes seen in lung adenocarcinomas. ${ }^{1}$ Hence, current biomarker-driven therapy is only available for oncogenic drivers that have been mainly identified in patients with non-squamous histology. ${ }^{2,8}$ Immunotherapy, on the other hand, has shown efficacy in patients regardless of histology, ${ }^{9-15}$ and has led to greatly improved outcomes in patients with squamous-cell carcinoma. However, overall, the outcomes in patients with squamous-cell carcinoma are not as encouraging as the outcomes in patients with adenocarcinoma. . $6,17^{-17}$

Current treatment guidelines for patients with metastatic squamous NSCLC recommend first-line treatment with immunotherapy plus chemotherapy, immunotherapy as monotherapy, or chemotherapy. ${ }^{18,19}$ However, at progression, recommended treatments include singleagent immunotherapy (if not given previously), docetaxel alone or in combination with ramucirumab, gemcitabine, or epidermal growth factor receptor (EGFR) tyrosine kinase inhibitors (TKIS). ${ }^{18,19}$ The oral route of administration of EGFR TKIs, such as afatinib, may represent an advantage over intravenous options. In this article we aim to summarize the data supporting the use of afatinib for patients with NSCLC of squamous histology.

\section{ErbB pathway dysregulation}

Dysregulation of the ErbB pathway occurs in lung squamous-cell carcinoma more frequently than it may be reported, since patients with lung adenocarcinoma are more likely to be tested and this provides a biological rationale suggesting that targeting the ErbB receptor family could be a valid therapeutic option for patients with squamous NSCLC. While EGFR mutations are rare in patients with squamous $\mathrm{NSCLC}_{1}^{2}$ high levels of EGFR expression and/or EGFR copy number alterations have been reported. ${ }^{20,21}$ EGFR overexpression and gene amplification aberrations of other ErbB receptors, as well as dysregulation of the downstream pathways, have been implicated in the pathobiology of squamous-cell carcinoma (Table 1). ${ }^{22,23-32}$ This dysregulation likely accounts for benefits that have been reported for patients receiving afatinib, ${ }^{33}$ erlotinib, ${ }^{34-36}$ or other EGFR-directed therapies in different treatment settings, ${ }^{37-40}$ despite the low frequency of EGFR-activating mutations. ${ }^{2,41}$

\section{Targeting epidermal growth factor receptor in squamous non-small cell lung cancer}

Patients with squamous NSCLC that does not harbour EGFR-activating mutations have been included in several clinical trials evaluating EGFRtargeting agents. The EGFR TKIs, erlotinib and afatinib, and the EGFR monoclonal antibody, necitumumab, are included in the treatment of patients with squamous NSCLC in their approved indications; although, the specific details differ between the USA and Europe. In the USA, necitumumab in combination with chemotherapy is indicated for firstline treatment of squamous NSCLC and in Europe, the indication specifies that the squamous NSCLC should be EGFR expressing, which was the
Table 1: ErbB receptor dysregulation in non-small cell lung cancer of squamous histology

\begin{tabular}{|l|l|}
\hline ErbB receptor dysregulation & Reported frequencies (\%) \\
\hline EGFR overexpression ${ }^{23-26}$ & $25-86$ \\
\hline EGFR amplification ${ }^{23,26}$ & $15-27$ \\
\hline EGFRVIII mutation ${ }^{27,28}$ & 5 \\
\hline EGFR mutation ${ }^{29}$ & $<5$ \\
\hline ErbB2 (HER2) mutation/amplification ${ }^{23}$ & 5 \\
\hline ErbB3 (HER3) mutation 30 & 1 \\
\hline ErbB3 (HER3) overexpression ${ }^{31}$ & 10 \\
\hline ErbB4 (HER4) ${ }^{32}$ & 8 \\
\hline
\end{tabular}

EGFR = epidermal growth factor receptor; HER = human epidermal growth factor receptor.

case for $95 \%$ of the patients in the pivotal SQUIRE trial. ${ }^{40,42}$ In Europe, erlotinib is indicated for the treatment of NSCLC after failure of at least one prior chemotherapy regimen, including patients with squamous NSCLC, based on the pivotal BR.21 trial. ${ }^{35}$ In the USA, the erlotinib label is limited only to patients with NSCLC with activating EGFR mutations. In both the USA and in Europe, afatinib is indicated for squamous NSCLC progressing after platinum-based chemotherapy.

\section{Afatinib in squamous non-small cell lung cancer: the LUX-Lung 8 trial}

Afatinib is an irreversible ErbB-family blocker, ${ }^{43}$ that covalently binds to all homodimers and heterodimers formed by EGFR, ErbB2 (human epidermal growth factor receptor 2 [HER2]), ErbB3 (HER3) and ErbB4 (HER4), and selectively blocks downstream signalling. ${ }^{44}$ Preclinically, afatinib has been shown to inhibit the activity of EGFR, ErbB2 (HER2) and ErbB4 (HER4), both in the wild-type and dysregulated forms, including uncommon EGFR mutations. ${ }^{43-45}$

LUX-Lung 8, a randomized, open-label, multinational, phase III trial, compared the efficacy of afatinib with that of erlotinib in patients with advanced squamous NSCLC progressing after at least four cycles of platinum-based chemotherapy. ${ }^{33}$ The study was conducted between 2012 and 2014 and enrolled patients with stage IIIB or IV NSCLC of squamous histology that had progressed following first-line platinumbased doublet chemotherapy. Treatment with prior EGFR-directed small molecules or antibodies was not allowed.

Erlotinib was chosen as the comparator since it was approved at the time, even in the USA, for the second-line treatment of patients with advanced stage squamous histology. However, erlotinib is not currently used in the USA in an unselected population after the USA Food and Drug Administration (FDA) label was modified in October 2016 limiting its use to NSCLC with activating EGFR mutations based on the results of the IUNO trial, ${ }^{46}$ a post-marketing commitment from the agency, and the 2016 National Comprehensive Cancer Network (NCCN) guidelines dropped the recommendation as a post-first-line or switch maintenance option in patients with squamous-cell carcinoma. ${ }^{47}$ As noted above, erlotinib is still used in Europe for this indication. ${ }^{48}$

Patients received afatinib at a starting dose of $40 \mathrm{mg}$ once daily or erlotinib at $150 \mathrm{mg}$ once daily until disease progression or unacceptable toxicity. The primary endpoint was progression-free survival (PFS) and the key secondary endpoint was overall survival (OS). EGFR testing was not mandated in this study; however, tumour tissue was collected for 
correlative science, and a post-hoc next-generation sequencing (NGS) analysis of archival tissue was conducted. The study enrolled 795 patients from 183 cancer centres in 23 countries. The median age of the patients was 64 years (range 35-88). Two-thirds of the patients had an Eastern Cooperative Oncology Group (ECOG) Performance Status (PS) of 1. In contrast to other studies with afatinib in EGFR-mutated NSCLC, most patients were men (84\%) and more than $90 \%$ of patients had a smoking history. Prior chemotherapy treatment was carboplatin-based in $60 \%$ of patients and cisplatin-based in $45 \%$ of patients and half of the patients had a response to this first-line treatment.

At the time of the primary analysis for OS with a database lock of March 2015, the mean exposure in the afatinib group was 121 days (range 2-840). One-tenth of the patients received the escalated dose of $50 \mathrm{mg}$ with a mean exposure of 106 days (range 4-588). Dose reductions of afatinib due to adverse events occurred in about one-third of the patients. Treatment with afatinib significantly prolonged PFS and OS compared with erlotinib. When $76 \%$ of PFS events and $79 \%$ of OS had occurred, there was a $19 \%$ reduction in the risk of progression or death in patients receiving afatinib (PFS hazard ratio [HR] 0.81 [95\% confidence interval $\{\mathrm{Cl}\}$ 0.69-0.96], $\mathrm{p}=0.0103$; and OS HR 0.81 [95\% $\mathrm{Cl} 0.69-0.95$ ], $\mathrm{p}=0.0077$ ). The OS rates for afatinib were $63.6 \%$ at 6 months, $36.4 \%$ at 12 months, and $22.0 \%$ at 18 months. Improvement in survival outcomes were seen across various patient subgroups (including ethnic origin, sex, best response to first-line chemotherapy, age < 65 or $\geq 65$ years, histology, ECOG PS). Patientreported outcomes indicated that patients receiving afatinib had an overall improvement for health-related quality of life (HRQOL) global health status $(p=0.041)$ as assessed using the European Organization for Research and Treatment of Cancer Quality of Life Questionnaire C30 (QLQ-C30), and the lung cancer-specific module, Quality of Life Questionnaire Lung Cancer-13 (QLQ-LC13), specifically with improvements in cough $(p=0.029)$ and delayed time to deterioration of dyspnoea $(p=0.008)$. $3.49^{33}$ In addition, treatment with afatinib had a favourable change in mean scores of prespecified lung cancer-related symptoms and global health status favoured afatinib for cough ( $p=0.0022)$, dyspnoea $(p=0.0007)$, pain $(p=0.0224)$, global health status/HRQOL $(p=0.0320){ }^{49}$

The safety profile in patients with squamous NSCLC is consistent with the known safety profile of afatinib, and includes diarrhoea, skin toxicities, fatigue and stomatitis as the most common side effects. ${ }^{50}$ Overall, the incidence of adverse events was similar in the afatinib and erlotinib arms (Table 2). Dose reduction of afatinib or discontinuation occurred in $15 \% / 4.1 \%$ of patients due to diarrhoea, $5.9 \% / 2.6 \%$ of patients due to rash/acne, and $3.1 \% / 1.0 \%$ of patients due to stomatitis. Serious adverse events were reported in $44 \%$ of patients receiving afatinib; the most frequent included pneumonia (6.6\%), diarrhoea (4.6\%), and dehydration and dyspnoea (3.1\% each).

At an updated analysis, with a data cut of March 2018 when only nine patients remained on treatment, OS continued to be significantly longer for afatinib than erlotinib (median OS of 7.8 months compared with 6.8 months; HR 0.84 [95\% Cl 0.73-0.97], $\mathrm{p}=0.019$ ). ${ }^{51}$ Remarkably, 5.3\% of the patients receiving afatinib derived long-term benefit. There were 21 of 398 patients in the afatinib arm who received treatment for longer than 12 months, for a median duration of 19.0 months (range, 12.351.3). In these patients with long-term disease control, the median OS was 27.5 months (range 16.2-53.6 months). The median PFS was 12.9 months (range 2.8-25.8) in the long-term responders compared with 2.6 months in the overall population that received afatinib (median PFS in patients receiving erlotinib was 1.9 months). One patient with longterm treatment with afatinib had a complete response, six patients had
Table 2: Treatment-related adverse events occurring in $>10 \%$ of patients with non-small cell lung cancer of squamous histology in LUX-Lung $8^{51}$

\begin{tabular}{|c|c|c|c|c|}
\hline \multirow[b]{2}{*}{$\%$} & \multicolumn{2}{|c|}{$\begin{array}{l}\text { Afatinib } \\
n=392\end{array}$} & \multicolumn{2}{|c|}{$\begin{array}{l}\text { Erlotinib } \\
n=395\end{array}$} \\
\hline & All & Grade $\geq 3$ * & All & Grade $\geq 3$ * \\
\hline Any $A E$ & 93 & 28 & 82 & 18 \\
\hline Diarrhoea & 70 & 10 & 34 & 3 \\
\hline Rash/acne $^{+}$ & 67 & 6 & 68 & 10 \\
\hline Stomatitis $^{+}$ & 28 & 4 & 8 & 0 \\
\hline Fatigue $^{+}$ & 8 & 1 & 7 & 1 \\
\hline Decreased appetite & 13 & 1 & 10 & 1 \\
\hline Nausea & 13 & 1 & 7 & 1 \\
\hline Paronychia $^{\dagger}$ & 10 & 1 & 4 & $<1$ \\
\hline
\end{tabular}

* Fatal AEs that were considered to be drug related were reported in six patients (1.5\%) receiving afatinib: interstitial lung disease (two patients), pneumonia (one patient), respiratory failure (one patient), acute renal failure (one patient) and general physical health deterioration (one patient), and in five patients (1.3\%) receiving erlotinib: interstitial lung disease, intestinal obstruction, pneumonia, pneumonitis and peritonitis (one patient each).

${ }^{\dagger}$ Grouped terms.

$A E=$ adverse event

a partial response, and 13 patients had stable disease as best response (Figure 1). Six patients required a dose reduction to $30 \mathrm{mg}$ and three required a further reduction to $20 \mathrm{mg}$. The frequency of dose-reductions due to diarrhoea (19.0\%), rash/acne (4.8\%), and stomatitis (4.8\%) was similar to the overall afatinib-treated population. None of the patients discontinued due to an adverse event.

\section{Squamous non-small cell lung cancer: ErbB pathway dysregulation}

To better assess the genetic characteristics of squamous NSCLC and characterize the ErbB gene family member aberrations, archival tumour tissue specimens collected at study entry from 245 patients (132 samples from patients receiving afatinib and 113 from patients receiving erlotinib) were evaluated through a comprehensive genetic NGS analysis using Foundation Medicine T7 (Foundation Medicine, Cambridge, MA, USA). ${ }^{52}$ In order to have a wide range of samples from patients with different responses to treatment, the samples selected for this ad hoc, retrospective secondary analysis were enriched to include patients with PFS longer than 2 months (61\% of the samples came from patients with a PFS $>2$ months although in the overall population only $43 \%$ of patients had a PFS $>2$ months). The NGS analyses were conducted from February 2015 to June 2017. Pre-treatment plasma samples from 675 patients were assessed using Veristrat ${ }^{\circledR}$ ([Biodesix, Boulder, CO, USA] a serum protein test shown to be predictive of response to EGFR TKIS) $)^{53}$ to assign a VeriStrat 'Good' or Veristrat 'Poor' classification. ${ }^{54}$ The NGS and Veristrat analyses were conducted from February 2015 to June 2017.

The NGS analyses of 245 patients found an ErbB mutation in 22\% of the patients (Table 3).50 Mutations were detected in EGFR, HER2, ErbB3 (HER3), and ErbB4 (HER4), with each mutation being report in approximately 5-6\% of patients. One patient had EGFR, HER2, and ErbB3 (HER3) mutations, and two patients had ErbB3 (HER3) and ErbB4 (HER4) mutations. Amplification of EGFR and HER2 was detected in 17 (6.9\%) and 9 (3.7\%) patients, respectively; however, no copy number alterations were detected in ErbB3 (HER3) or ErbB4 (HER4). ${ }^{52}$ The PFS and OS outcomes in the 245 patients with samples undergoing NGS analyses also favoured treatment with afatinib (PFS HR 0.69 [95\% $\mathrm{Cl} 0.51-0.92], p=0.01$; and OS HR 0.81 [95\% Cl 0.62-1.05], $p=0.12$ ). 
Figure 1: Swimmers plot for patients deriving long-term benefit from afatinib $(n=21)^{51}$

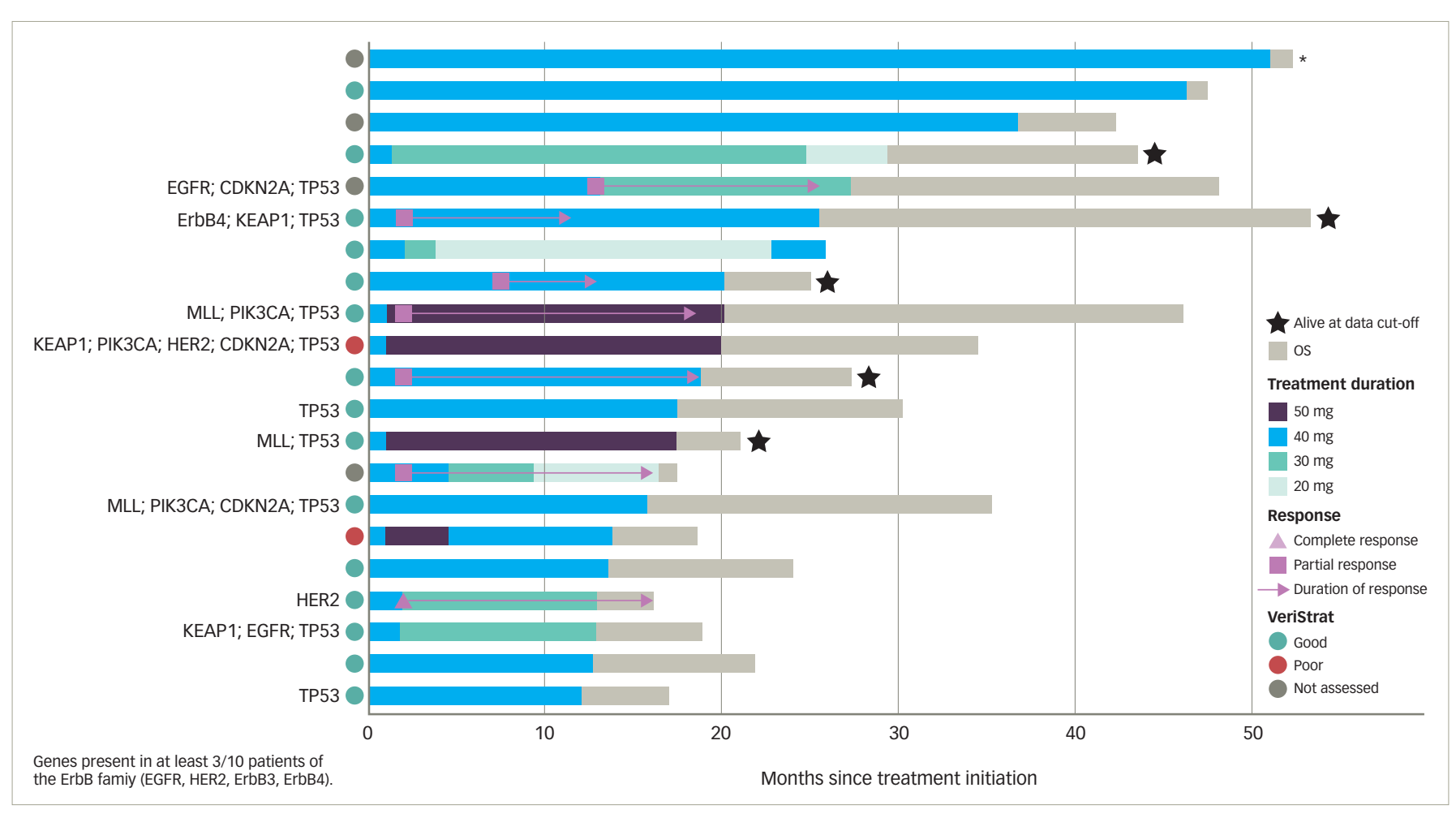

* Patient transferred to commercial drug on discontinuation from study drug.

$E G F R=$ epidermal growth factor receptor; $H E R=$ human epidermal growth factor receptor; OS = overall survival.

Table 3: ErbB family mutations in non-small cell lung cancer of squamous histology in LUX-Lung $8^{51,52}$

\begin{tabular}{|l|l|l|l|}
\hline$n(\%)$ & $\begin{array}{l}\text { All NGS samples } \\
\text { (afatinib and } \\
\text { erlotinib) } \\
\mathrm{n}=245\end{array}$ & $\begin{array}{l}\text { All afatinib } \\
\text { samples } \\
\mathrm{n}=132\end{array}$ & $\begin{array}{l}\text { Long-term } \\
\text { afatinib } \\
\text { samples } \\
\mathrm{n}=10\end{array}$ \\
\hline ErbB wild type & $192(78.4)$ & $107(81.1)$ & $5(50.0)$ \\
\hline ErbB mutation & $53(21.6)$ & $25(18.9)$ & $5(50.0)$ \\
\hline EGFR & $16(6.5)$ & $9(6.8)$ & $2(20.0)$ \\
\hline ErbB2 (HER2) & $12(4.9)$ & $9(6.8)$ & $2(20.0)$ \\
\hline ErbB3 (HER3) & $15(6.1)$ & $6(4.5)$ & 0 \\
\hline ErbB4 (HER4) & $14(5.7)$ & $3(2.3)$ & $1(10.0)$ \\
\hline
\end{tabular}

EGFR = epidermal growth factor receptor; HER = human epidermal growth factor receptor; NGS = next-generation sequencing.

Samples were available for NGS analyses in 10 long-term responding patients and, overall, in 132 patients in the afatinib arm. ${ }^{51}$ Interestingly, ErbB family mutations were more frequent in patients with long-term disease control. Overall, ErbB mutations were detected in $19 \%$ of patients receiving afatinib while $50 \%$ of patients receiving long-term treatment with afatinib had a mutation. Amongst three patients who received longterm erlotinib there was one patient with EGFR-mutated NSCLC and the other two had ErbB wild type.

\section{Afatinib outcomes in squamous non-small cell lung cancer with ErbB pathway dysregulation}

In patients receiving afatinib, both PFS and OS were longer in patients with squamous NSCLC harbouring ErbB mutations..$^{55}$ The median PFS was 4.9 months in patients with ErbB mutation versus 3.0 months in patients without the mutation (HR 0.62 [95\% $\mathrm{Cl} 0.37-1.02], \mathrm{p}=0.06$ ). Median OS also favoured afatinib with 10.6 months versus 8.1 months in patients with and without ErbB mutations, respectively (HR 0.75 [95\% Cl 0.471.17], $p=0.21$ ), but there was no apparent association between copy number alteration or EGFR expression level and outcome.

Treatment with afatinib improved outcomes compared with erlotinib across all ErbB family mutation subgroups (Table 4). However, there was a pronounced benefit for patients with a HER2 mutation, with significant interaction $p$ values for both PFS $(p=0.006)$ and OS $(p=0.003)$, suggesting that the presence of this mutation could predict better outcomes with afatinib compared with erlotinib. There were 12 patients with NSCLC with a HER2 mutation and PFS and OS both strongly favoured treatment with afatinib (PFS HR 0.06 [95\% Cl 0.01-0.59], $p=0.02$; and OS HR 0.06 [95\% Cl $0.01-0.57], p=0.02$ ).

Among the patients deriving long-term benefit from afatinib and with genetic information available ( $n=10)$, two had a HER2 mutation (Figure 1). Not shown in the figure is a patient with an R847H mutation in exon 21 of ErbB4 (HER4) who was progression-free for 448 days (14.7 months) according to the investigator review, although, the independent review noted that progression had occurred after 278 days (9.1 months) of treatment. ${ }^{56}$ Overall, the patient received afatinib for a total of 504 days (16.6 months). Interestingly, afatinib showed efficacy in a patient with squamous NSCLC harbouring a rare HER2 R896G mutation, with a PFS of $>14$ months. ${ }^{57}$

Patients were mostly classified as Veristrat 'Good' (412 patients, $61 \%$ ) and in this patient subgroup, treatment with afatinib also led to an improvement in OS (HR 0.79 [95\% Cl 0.63-0.98]). ${ }^{54}$ There were 263 patients (39\%) who were classified as Veristrat 'Poor' with no significant differences in OS between afatinib and erlotinib (HR 0.90 [95\% Cl 0.701.16]). Using the Veristrat classification may also help guide treatment 
Table 4: Progression-free survival outcomes according to ErbB mutations in non-small cell lung cancer of squamous histology in LUX-Lung $8^{52}$

\begin{tabular}{|l|l|l|}
\hline \multirow{2}{*}{ EGFR } & Present $(\mathrm{n}=16)$ & $0.64(0.17-2.44)$ \\
\cline { 2 - 3 } & Absent $(\mathrm{n}=229)$ & $0.67(0.50-0.91)$ \\
\hline \multirow{2}{*}{ ErbB2 (HER2) } & Present $(\mathrm{n}=12)$ & $0.06(0.01-0.59)$ \\
\cline { 2 - 3 } & Absent $(\mathrm{n}=233)$ & $0.72(0.54-0.97)$ \\
\hline \multirow{2}{*}{ ErbB4 (HER4) } & Present $(\mathrm{n}=15)$ & $0.52(0.16-1.72)$ \\
\hline \multirow{2}{*}{ Any ErbB mutation } & Absent $(\mathrm{n}=230)$ & $0.69(0.51-0.94)$ \\
\hline \multirow{2}{*}{$\begin{array}{l}\text { Any ErbB mutation } \\
\text { (except EGFR) }\end{array}$} & Present $(\mathrm{n}=14)$ & $0.21(0.02-1.94)$ \\
\hline & Absent $(\mathrm{n}=231)$ & $0.67(0.50-0.91)$ \\
\hline & Present $(\mathrm{n}=53)$ & $0.56(0.29-1.08)$ \\
\hline & Absent $(\mathrm{n}=192)$ & $0.70(0.50-0.97)$ \\
\hline & Present $(\mathrm{n}=38)$ & $0.44(0.19-0.99)$ \\
\hline & Absent $(\mathrm{n}=207)$ & $0.71(0.52-0.98)$ \\
\hline
\end{tabular}

$H R<1$ favours treatment with afatinib compared with erlotinib.

$\mathrm{Cl}=$ confidence interval; $\mathrm{EGFR}=$ epidermal growth factor receptor; $\mathrm{HER}=$ human epidermal growth factor receptor; HR = hazard ratio.

decisions for patients with squamous NSCLC. A higher percentage of patients deriving long-term benefit from afatinib were classified as Veristrat 'Good' (88\%) compared with the overall group of patients receiving afatinib (62\%).

\section{Summary and future directions}

The use of immunotherapy with immune checkpoint inhibitors, either as monotherapy or in combination with chemotherapy, is now established as the preferred first-line treatment option for patients with advanced NSCLC of squamous histology, and this requires the need to optimize subsequent treatment decisions. ${ }^{1.19}$ At the moment, none of the secondline therapies have been approved with a first-line regimen that includes immunotherapy, since the standard of care at the time that the studies were conducted was a platinum-chemotherapy regimen. However, upon disease progression, any second-line options should consider that most patients will be in an immunotherapy refractory state and hence, the immunotherapy agents approved in this setting (nivolumab, pembrolizumab, atezolizumab) are unlikely to be administered, instead turning towards a chemotherapy regimen or an EGFR inhibitor.

Although there are several genomic alterations that characterize squamous NSCLC, with PI3K alterations or FGFR1 amplification being the most common, ${ }^{1,41}$ these are little data to suggest that targeting these alterations may have any clinical relevance. The Lung-MAP SWOG S1400 biomarkerdriven master protocol was designed to address an unmet need for better therapies for squamous NSCLC. ${ }^{58}$ However, results in biomarker-driven sub-studies targeting PI3K, FGFR1 or cell cycle gene alterations have been unsatisfactory. The ErbB receptor has been identified as a potential therapeutic target in squamous-cell lung cancer as it plays a pivotal role in the transduction of cell growth-stimulatory signals. ${ }^{41}$

Many studies have evaluated the efficacy of targeting EGFR in NSCLC considering different EGFR biomarkers for the selection of patients. Findings from the phase III FLEX study in chemotherapy-naïve patients with EGFR-expressing NSCLC (85\% of patients assessed) showed significantly longer survival in patients given chemotherapy plus the
EGFR antibody cetuximab than those in the chemotherapy-alone group (median OS 11.3 versus 10.1 months; HR 0.871 [95\% Cl 0.7620.996]), with survival benefit seen in prespecified histology subgroups analyses including squamous-cell carcinoma (median os 10.2 versus 8.9 months; HR 0.80 [95\% $\mathrm{Cl} 0.64-1.00]]^{38}$ and much better outcomes in squamous NSCLC selected for high EGFR expression (H-score $\geq 200$ ) (median OS 11.2 versus 8.9 months; HR 0.62 [95\% Cl $0.43-0.88]$ ]. ${ }^{39}$ In the first-line SWOG S0819, EGFR positivity by EGFR copy number by fluorescence in-situ hybridization in patients with NSCLC was associated with significantly improved OS with cetuximab treatment (11.8 months) versus chemotherapy alone (6.1 months; HR 0.58 [95\% $\mathrm{Cl}$ 0.39-0.86], $\mathrm{p}=0.0071)$. However, the co-primary endpoint of PFS did not differ between treatment groups. ${ }^{59}$ Moreover, in the first-line phase III study BMS099 of cetuximab in advanced NSCLC, there was no difference in median os between patients receiving cetuximab plus chemotherapy compared with chemotherapy alone, ${ }^{60}$ and there was no significant association between response to treatment and any biomarkers status including EGFR expression, mutation, or gene copy number. ${ }^{61}$ Other studies in the second-line setting have also failed to report better outcomes with cetuximab compared with docetaxel with no signs of interaction with EGFR expression (H-score 200 cut-off). ${ }^{62}$ There have also been conflicting results from studies with erlotinib that have looked at biomarkers in the setting of squamous NSCLC. ${ }^{63}$

In the LUX-Lung 8 study, afatinib significantly improved PFS and OS compared with erlotinib. ${ }^{33,51}$ Secondary analyses found that ErbB receptor family alterations may explain the benefit observed and may help better identify patients who could derive better outcomes. Notably, patients achieving long-term benefit that was defined as receiving afatinib treatment for $\geq 12$ months had a median os of 27.5 months and reported more frequent ErbB family mutations than patients who received afatinib for less than 1 year. On the whole, about one-fifth of the patients had ErbB mutation-positive tumours and in these patients, there was a more pronounced PFS and OS benefit with afatinib compared with erlotinib, particularly in patients with HER2 mutations. ${ }^{52}$

Although three therapeutic agents targeting EGFR have been approved for the treatment of squamous-cell lung cancer (afatinib, erlotinib, necitumumab), the most appropriate biomarker for the selection of patients for treatment with agents targeting EGFR in squamous-cell lung cancer remains to be determined. It is important to note that most of the studies did not prospectively analyse the outcomes in biomarker defined populations. In fact, the studies supporting the approval of afatinib, erlotinib, and necitumumab were conducted in a squamous-cell carcinoma population that was not biomarker-selected, hence the broad approval in the overall population.

Taken as a whole, afatinib should be considered for patients with advanced squamous-cell carcinoma of the lung, as a treatment option in patients with disease that has failed previous treatment with chemotherapy and immunotherapy, and in the second-line setting in patients who are not eligible for immune checkpoint inhibitors. An increased use of NGS testing, not only in non-squamous NSCLC, but also in squamous histology, including ErbB family mutations, is warranted to identify patients with squamous-cell lung cancer who could benefit from treatment with afatinib, and to further evaluate the role of HER2 mutations as predictive biomarkers for afatinib. $\square$ 
1. Paik PK, Pillai RN, Lathan CS, et al. New treatment options in advanced squamous cell lung cancer. Am Soc Clin Oncol Educ Book. 2019:39:e198-e206.

2. Li T, Kung HJ, Mack PC, Gandara DR. Genotyping and genomic profiling of non-small-cell lung cancer: implications for current and future therapies. J Clin Oncol. 2013:31:1039-49.

3. Gandara DR, Hammerman PS, Sos ML, et al. Squamous cell lung cancer. from tumor genomics to cancer therapeutics. Clin Cancer Res. 2015;21:2236-43.

4. Johnson DH, Fehrenbacher L, Novotny WF, et al. Randomized phase II trial comparing bevacizumab plus carboplatin and paclitaxel with carboplatin and paclitaxel alone in previously untreated locally advanced or metastatic non-small-cell lung cancer. J Clin Oncol. 2004;22:2184-91.

5. Al-Saleh K, Quinton C, Ellis PM. Role of pemetrexed in advanced non-small-cell lung cancer:meta-analysis of randomized controlled trials, with histology subgroup analysis. Curr Oncol. 2012;19:e9-15.

6. Scagliotti GV, Parikh P, von Pawel J, et al. Phase III study comparing cisplatin plus gemcitabine with cisplatin plus pemetrexed in chemotherapy-naive patients with advancedstage non-small-cell lung cancer. J Clin Oncol. 2008;26:3543-51.

7. Paz-Ares $L G$, de Marinis F, Dediu M, et al. PARAMOUNT: final overall survival results of the phase III study of maintenance pemetrexed versus placebo immediately after induction treatment with pemetrexed plus cisplatin for advanced nonsquamous non-small-cell lung cancer. J Clin Oncol. 2013;31:2895-902

8. Sabari JK, Paik PK. Relevance of genetic alterations in squamous and small cell lung cancer. Ann Trans/ Med. 2017; 5:373

9. Reck M, Rodriguez-Abreu D, Robinson AG, et al. Pembrolizumab versus chemotherapy for PD-L1-positive non-small-cell lung cancer. N Engl J Med. 2016;375:1823-33.

10. Mok TSK, Wu YL, Kudaba I, et al; KEYNOTE-042 Investigators. Pembrolizumab versus chemotherapy for previously untreated PD-L1-expressing, locally advanced or metastatic non-smallcell lung cancer (KEYNOTE-042): a randomised, open-label, controlled, phase 3 trial. Lancet. 2019;393:1819-30.

11. Paz-Ares $L$, Luft $A$, Vicente $D$, et al. Pembrolizumab plus chemotherapy for squamous non-small-cell lung cancer. N Eng J Med. 2018;379:2040-51.

12. Jotte R, Cappuzzo F, Vynnychenko I, et al. Atezolizumab in combination with carboplatin and nab-paclitaxel in advanced squamous nsclc (impower131): results from a randomized phase III trial. J Thorac Oncol 2020;15:1351-60.

13. Hellmann MD, Ciuleanu TE, Pluzanski A, et al. Nivolumab (nivo) + ipilimumab (ipi) vs platinum-doublet chemotherapy (PT-DC) as first-line (1L) treatment (tx) for advanced non-small cell lung cancer (NSCLC): initial results from CheckMate 227. Cancer Res 2018;78(Suppl 13):CT077.

14. Hellmann MD, ciuleanu TE, Pluzanski A, et al. Nivolumab plus Ipilimumab in lung cancer with a high tumor mutational burden N Engl J Med. 2018;378:2093-104.

15. Hellmann MD, Paz-Ares L, Bernabe Caro R, et al. Nivolumab plus ipilimumab in advanced non-small-cell lung cancer. N Eng J Med. 2019;381:2020-31.

16. Borghaei H, Gettinger S, Vokes EE, et al. Five-year outcomes from the randomized, phase III trials CheckMate 017 and $05 \%$ nivolumab versus docetaxel in previously treated non-smallcell lung cancer. I Clin Oncol. 2021;39:723-33.

17. Horn L, Spigel DR, Vokes EE, et al. Nivolumab versus docetaxel in previously treated patients with advanced non-small-cell lung cancer: two-year outcomes from two randomized, openlabel, phase III trials (CheckMate 017 and CheckMate 057). J Clin Oncol. 2017;35:3924-33.

18. National Comprehensive Cancer Network (NCCN). NCCN Clinical Practice Guidelines in Oncology. Non-small cell lung clinical Practice Guidelines in Oncology. Non-small cell lung cancer, 2020. Available at: www.nccn.org/professionals/
physician_gls/pdf/nscl.pdf (accessed 31 January 2021).

19. Planchard D, Popat S, Kerr K, et al. Metastatic non-smal cell lung cancer: ESMO clinical practice guidelines for diagnosis, treatment and follow-up. Ann Oncol. 2018;29(Suppl 4): iv192-237.

20. Sharma N, Graziano S. Overview of the LUX-Lung clinical trial program of afatinib for non-small cell lung cancer. Cancer Treat Rev. 2018:69:143-51.

21. Hirsh $V$. New developments in the treatment of advanced squamous cell lung cancer: focus on afatinib. Onco Targets Ther. 2017;10:2513-26.

22. Hirsch FR, Varella-Garcia M, Bunn PA Jr, et al. Epidermal growth factor receptor in non-small-cell lung carcinomas: correlation between gene copy number and protein expression and impact on prognosis. J Clin Oncol. 2003:21:3798-807.

23. Lopez-Malpartida AV, Ludena MD, Varela G, Garcia Pichel
1. Differential ErbB receptor expression and intracellular signaling activity in lung adenocarcinomas and squamous cel carcinomas. Lung Cancer. 2009;65:25-33.

24. Lee HJ, Xu X, Choe G, et al. Protein overexpression and gene amplification of epidermal growth factor receptor in nonsmall cell lung carcinomas: comparison of four commercially available antibodies by immunohistochemistry and fluorescence in situ hybridization study. Lung Cancer. 2010;68:375-82

25. Gately K, Forde L, Cuffe S, et al. High coexpression of both EGFR and IGF1R correlates with poor patient prognosis in resected non-small-cell lung cancer. Clin Lung Cancer. 2014;15:58-66.

26. Dacic S, Flanagan M, Cieply K, et al. Significance of EGFR protein expression and gene amplification in non-small cel lung carcinoma. Am J Clin Pathol. 2006;125:860-5.

27. Ji H, Zhao X, Yuza Y, et al. Epidermal growth factor receptor variant III mutations in lung tumorigenesis and sensitivity to tyrosine kinase inhibitors. Proc Natl Acad Sci USA. 2006;103:7817-22.

28. Duan J, Wang Z Bai $\mathrm{H}$, et al. Epidermal growth factor receptor variant III mutation in Chinese patients with squamous cell cancer of the lung. Thorac Cancer. 2015;6:319-26.

29. Dearden S, Stevens J, Wu YL, Blowers D. Mutation incidence and coincidence in non small-cell lung cancer: meta-analyses by ethnicity and histology (mutMap). Ann Oncol. 2013;24:2371-6.

30. Jaiswal BS, Kljavin NM, Stawiski EW, et al. Oncogenic ERBB3 mutations in human cancers. Cancer Cell. 2013;23:603-17.

31. Gorgoulis V, Sfikakis PP, Karameris A, et al. Molecular and immunohistochemical study of class I growth factor receptors in squamous cell lung carcinomas. Pathol Res Pract. 1995; 191:973-81.

32. Kan Z, Jaiswal BS, Stinson J, et al. Diverse somatic mutation patterns and pathway alterations in human cancers. Nature 2010;466:869-73

33. Soria JC, Felip E, Cobo M, et al. Afatinib versus erlotinib as second-line treatment of patients with advanced squamous cell carcinoma of the lung (LUX-Lung 8): an open-label randomised controlled phase 3 trial. Lancet Oncol. 2015;16:897-907.

34. Clark GM, Zborowski DM, Santabarbara P, et al. Smoking history and epidermal growth factor receptor expression as predictors of survival benefit from erlotinib for patients with non-small-cell lung cancer in the National Cancer Institute of Canada Clinica Trials Group study BR.21. Clin Lung Cancer. 2006;7:389-94.

35. Shepherd FA, Rodrigues Pereira J, Ciuleanu T, et al. Erlotinib in previously treated non-small-cell lung cancer. N Eng/ I Med. 2005;353:123-32

36. Tsao MS, Sakurada A, Cutz JC, et al. Erlotinib in lung cancer molecular and clinical predictors of outcome. N Eng/ I Med. 2005;353:133-44

37. Ciuleanu T, Socinski MA, Obasaju C, et al. Efficacy and safety of necitumumab continuation therapy in the phase III SQUIRE study of patients with stage IV squamous non-small-cell lung cancer Clin Lung Cancer 2018:19:130-8.

38. Pirker R, Pereira JR, Szczesna A, et al. Cetuximab plus chemotherapy in patients with advanced non-small-cell lung cancer (FLEX):an open-label randomised phase III trial. Lancet. 2009;373:1525-31

39. Pirker R, Pereira JR, von Pawel J, et al. EGFR expression as a predictor of survival for first-line chemotherapy plus cetuximab in patients with advanced non-small-cell lung cancer: analysis of data from the phase 3 FLEX study. Lancet Oncol. 2012;13:33-42

40. Thatcher N, Hirsch FR, Luft AV, et al. Necitumumab plus gemcitabine and cisplatin versus gemcitabine and cisplatin alone as first-line therapy in patients with stage IV squamous non-small-cell lung cancer (SQUIRE):an open-label, randomised, controlled phase 3 trial. Lancet Oncol. 2015;16:763-74.

41. The Cancer Genome Atlas Research Network. Comprehensive genomic characterization of squamous cell lung cancers. Nature. 2012;489:519-25

42. Paz-Ares L, Socinski MA, Shahidi J, et al. Correlation of EGFRexpression with safety and efficacy outcomes in SQUIRE: a randomized, multicenter, open-label, phase III study of gemcitabine-cisplatin plus necitumumab versus gemcitabinecisplatin alone in the first-line treatment of patients with stage IV squamous non-small-cell lung cancer. Ann Oncol. 2016;27:1573-9.

43. Li D, Ambrogio L, Shimamura T, et al. BIBW2992, an irreversible EGFR/HER2 inhibitor highly effective in preclinical lung cancer models. Oncogene. 2008;27:4702-11.

44. Solca F, Dahl G, Zoephel A, et al. Target binding properties and cellular activity of afatinib (BIBW 2992), an irreversible ErbB family blocker. J Pharmacol Exp Ther. 2012;343:342-50.

45. Suzawa K, Toyooka S, Sakaguchi M, et al. Antitumor effect of afatinib, as a human epidermal growth factor receptor 2-targeted therapy, in lung cancers harboring HER2 oncogene alterations. Cancer Sci. 2016:107:45-52

46. Cicènas $\mathrm{S}$, Geater SL, Petrov P, et al. Maintenance erlotinib versus erlotinib at disease progression in patients with advanced non-small-cell lung cancer who have not progressed following platinum-based chemotherapy (IUNO study). Lung Cancer 2016:102:30-7.

47. International Assocciation for the Study of Lung Cancer. National Comprehensive Cancer Network NSCLC guidelin updates for 2016: non-small cell lung cancer. Available at: www.iaslc.org/iaslc-news/ilcn/national-comprehensivecancer-network-nsclc-guideline-updates-2016-non-small-cell (accessed 31 January 2021).

48. Debieuvre D, Moreau L, Coudert M, et al. Second- or third-line treatment with erlotinib in EGFR wild-type non-small cell lung cancer. real-life data. Rev Mal Respir. 2019;36:649-63.

49. Felip E, Hirsh V, Popat $\mathrm{S}$, et al. Symptom and quality of life improvement in LUX-lung 8, an open-label phase III study of second-line afatinib versus erlotinib in patients with advanced squamous cell carcinoma of the lung after first-line platinumbased chemotherapy. Clin Lung Cancer 2018;19:74-83.e11.

50. Sartori G, Belluomini L, Lombardo F, et al. Efficacy and safety of afatinib for non-small-cell lung cancer: state-of-the-art and future perspectives. Expert Rev Anticancer Ther. 2020;20:531-42.

51. Goss GD, Cobo M, Lu S, et al. Afatinib versus erlotinib as second-line treatment of patients (pts) with advanced lung squamous cell carcinoma (SCC): final analysis of the globa phase III LUX-Lung 8 (LL8) trial. Ann Oncol. 2018;29:viii521.

52. Goss GD, Felip E, Cobo M, et al. Association of ERBB mutations with clinical outcomes of afatinib- or erlotinib-treated patients with lung squamous cell carcinoma:secondary analysis of the LUX-Lung 8 randomized clinical trial. JAMA Oncol. 2018:4:1189-97.

53. Gregorc $V$, Novello $S$, Lazzari $C$ et al. Predictive value of a proteomic signature in patients with non-small cell lung cancer treated with second-line erlotinib or chemotherapy (PROSE): a biomarker-stratified randomized phase 3 trial Lancet Oncol. 2014;15:713-21.

54. Gadgeel S, GosS G, Soria JC, et al. Evaluation of the veristrat ® serum protein test in patients with advanced squamous cell carcinoma of the lung treated with second-line afatinib or erlotinib in the phase III LUX-Lung 8 study. Lung Cancer. 2017;109:101-8.

55. Yang JCH, Goss G, Felip E, et al. LUX-Lung 8 phase III trial: analysis of long-term response to second-line afatinib in patients with advanced squamous cell carcinoma (SCC) of the lung. Ann Oncol 2017:28:ii37.

56. Jian $\mathrm{H}, \mathrm{Han} Y, Y$ Y Y, Lu S. Long-term efficacy of afatinib in a patient with squamous cell carcinoma of the lung and multiple ERBB family aberrations:afatinib in ERBB + lung squamous cell carcinoma. Anticancer Drugs. 2019:30:873-8.

57. Lin L, Ge H, Yan Z. Wang $G$, Wu X, LV D. Response to afatinib in a patient with non-small cell lung cancer harboring HER2 R896G mutation: a case report. Onco Targets Ther. 2019;12:10897-902

58. Redman MW, Papadimitrakopoulou VA, Minichiello K et al. Biomarker-driven therapies for previously treated squamous non-small-cell lung cancer (Lung-MAP SWOG S1400): a biomarker-driven master protocol. Lancet Oncol. 2020;21:1589-601.

59. Herbst RS, Redman MW, Kim ES, et al. Cetuximab plus carboplatin and paclitaxel with or without bevacizumab versus carboplatin and paclitaxel with or without bevacizumab in advanced NSCLC (SWOG S0819): a randomised, phase 3 study. Lancet Oncol. 2018:19:101-14.

60. Lynch $T$, Patel T, Dreisbach $L$, et al. Cetuximab and first-line taxane/carboplatin chemotherapy in advanced non-small-cell lung cancer:results of the randomized multicenter phase III tria BMS099. J Clin Oncol. 2010:28:911-7.

61 Khambata-Ford S, Harbison CT, Hart $\amalg$ et al. Analysis of potential predictive markers of cetuximab benefit in BMS099, a phase III study of cetuximab and first-line taxane/carboplatin in advanced non-small-cell lung cancer. J Clin Oncol. 2010;28:918-27.

62. Kim ES, Neubauer M, Cohn A et al. Docetaxel or pemetrexed with or without cetuximab in recurrent or progressive nonsmall-cell lung cancer after platinum-based therapy:a phase 3 , open-label, randomised trial. Lancet Oncol. 2013:14:1326-36.

63. Peters S, Stahel RA, Dafni U, et al. EMPHASIS-lung Collaborative Group. Randomized phase III trial of erlotinib versus docetaxel in patients with advanced squamous cell non-small cell lung cancer failing first-line platinum-based doublet chemotherapy stratified by veristrat good versus veristrat poor. the european thoracic oncology platform (ETOP) EMPHASIS-lung european thoracic oncology platform
trial. J Thorac Oncol. 2017:12:752-62. 